\title{
Modeling and Predicting Mobile Phone Touchscreen Transcription Typing Using an Integrated Cognitive Architecture
}

\author{
Shi $\mathrm{Cao}^{1}$, Anson $\mathrm{Ho}^{1}$, and Jibo $\mathrm{He}^{2}$ \\ 1: Department of Systems Design Engineering, University of Waterloo; \\ 2: Psychology Department, Wichita State University.
}

\begin{abstract}
Modeling typing performance has values in both the theory and design practice of human-computer interaction. Previous models have simulated desktop keyboard transcription typing performance; however, as the increasing prevalence of smartphones, new models are needed to account for mobile phone touchscreen typing. In the current study, we built a model for mobile phone touchscreen typing in an integrated cognitive architecture and tested the model by comparing simulation results with human results. The results showed that the model could simulate and predict interkey time performance in both number typing (Experiment 1) and sentence typing (Experiment 2) tasks. The model produced results similar to the human data and captured the effects of digit/letter position and interkey distance on interkey time. The current work demonstrated the predictive power of the model without adjusting any parameters to fit human data. The results from this study provide new insights into the mechanism of mobile typing performance and support future work simulating and predicting detailed human performance in more complex mobile interaction tasks.
\end{abstract}

Keywords: transcription typing, mobile typing, interkey time, human performance modeling, QN-ACTR 


\section{INTRODUCTION}

Transcription typing, as one of the most fundamental activities in human-computer interaction, has received a considerable amount of research attention in the field of human factors (Gentner, 1983; Keith \& Ericsson, 2007; Logan \& Crump, 2009; Salthouse \& Scott, 1987). In addition to empirical studies identifying factors that affect typing performance, modeling work has also been conducted to build models that can estimate and simulate human typing performance. These models are valuable for practical applications that support interface design and evaluation. Also, modeling transcription typing performance has been used to demonstrate the capability of computational cognitive architectures (Cao \& Liu, 2013; St. Amant, Goodwin, Domınguez, \& Roberts, 2015; Wu \& Liu, 2008). While previous work mainly focused on modeling desktop keyboard typing, there is a need for models that can simulate mobile phone touchscreen typing. In the current study, we developed and validated a model that can simulate and predict mobile phone touchscreen typing interkey time performance. Our approach used an integrated cognitive architecture (i.e., QN-ACTR, introduced later in this paper), which considered both task descriptions (e.g., an operator's knowledge about the task procedure) and human constraints (e.g., time needed to process information or perform actions).

The current study includes two experiments. Because previous QN-ACTR models can simulate desktop keyboard typing performance (Cao \& Liu, 2013), we revised the previous model and adopted new assumptions to accommodate mobile touchscreen typing. In Experiment 1, the new model was tested in the simulation of a number typing task. Model fitness was examined using human data available from a previous study. In 
Experiment 2, the model developed from Experiment 1, without adjusting any parameters, was used to predict sentence typing performance on touchscreen mobile phones. An empirical study was conducted to collect human data for model validation. The following paragraphs review related literature in this research field.

Existing models that can simulate typing performance mainly focused on desktop keyboard typing tasks. One example is Keystroke-Level Model (KLM) (Card, Moran, \& Newell, 1980). KLM assumes that task execution can be decomposed into a series of operators, including Keystroking, Pointing, Homing the hands, Drawing, Mentally preparing, and Response of the machine system. Total execution time is the sum of all the operators' time values, which can be looked up from a predetermined table. Later in 1983, Card, Moran, and Newell introduced a more sophisticated modeling approach using GOMS (Goals, Operators, Methods, and Selection rules) as the task description method and MHP (Model Human Processor) as the cognitive architecture providing human constraints (Card, Moran, \& Newell, 1983). Since then the GOMS/MHP approach has been further developed and now has several variants (for details, see John \& Kieras, 1996). Based on the framework of MHP, a theory of skilled typing performance called TYPIST (John, 1996) was proposed and evaluated with respect to 30 typing phenomena (on desktop keyboards) identified in the literature (Salthouse, 1986). TYPIST could predict 20 of the 30 phenomena, and the remaining 10 were beyond the scope of TYPIST (John, 1996). In a recent work (St. Amant et al., 2015), researchers integrated TYPIST into the ACT-R (Adaptive Control of Thought-Rational) cognitive architecture (Anderson et al., 2004), and it was demonstrated that the integrated model could predict 12 basic typing phenomena. 
Another line of research modeled typing performance using Queueing Network (QN). QN models have been used to represent fundamental cognitive structures and simulate human performance (Liu, 1996, 2007). Integrating the GOMS/MHP and QN, Queueing Network-Model Human Processor (QN-MHP) has further developed the MHP architecture into a queueing network and taken the advantages of QN for multitask scheduling and workload representation (Liu, 1997; Liu, Feyen, \& Tsimhoni, 2006; Liu, Wu, \& Berman, 2012; Wu \& Liu, 2007). Using QN-MHP, researchers were able to model 32 of the 34 transcription typing (desktop keyboard) phenomena accumulated in the literature (Wu \& Liu, 2008). The remaining two phenomena are related to reading comprehension. This limitation is rooted in MHP, which has no mechanism to model the details of complex cognitive activities such as memory retrieval and reading comprehension. Addressing this issue, a recent work (Cao \& Liu, 2013) has integrated QN and ACT-R, adding ACT-R's strength in modeling complex cognition. The integrated architecture is named QN-ACTR. QN-ACTR covers ACT-R's modeling mechanisms, so it could incorporate previous models built in ACT-R.

Using QN-ACTR, Cao and Liu (2013) were able to model desktop transcription typing tasks including the ones related to reading comprehension. The results demonstrated that queues added in the motor sub-network are necessary for the model to type as rapidly as human typists because the queues allow the central production module to send motor typing commands in the unit of a word rather than each individual letter. While the letters are queued in the motor sub-network for processing, the production module can continue to process the next production rule, which produces interkey time similar to human results. In summary, QN-ACTR is able to model the most desktop 
typing phenomena and integrate techniques from both QN and ACT-R lines of research. Therefore, we chose QN-ACTR in the current study and further developed its capability of modeling mobile phone touchscreen typing.

With the increasing popularity of touchscreen mobile devices, there is an increasing need for models that can predict mobile touchscreen typing performance. Mobile typing is a task substantially different from desktop keyboard typing due to the reduced typing space and the use of touchscreens (Hoggan, Brewster, \& Johnston, 2008; James \& Reischel, 2001). Mobile phone typing often involves only one finger (i.e., the thumb) moving across all keys. Also in contrast to desktop keyboard typing, where typists could type without looking at the keys, mobile typing usually requires visual attention on the keys. Researchers have found that users' eye gaze positions switch between the text display area and the keyboard area when typing on a mobile phone (Holleis, Otto, Hussmann, \& Schmidt, 2007). On mobile devices that use touchscreens and virtual keyboards, the lack of physical cues and tactile feedback increases the need of visual attention to locate the correct key position. Due to these factors, mobile touchscreen typing speed is usually within the range of 20 to $40 \mathrm{wpm}$ (words per minute) (MacKenzie, Nonnecke, McQueen, Riddersma, \& Meltz, 1994; MacKenzie \& Soukoreff, 2002b; Silfverberg, MacKenzie, \& Korhonen, 2000; Turner, Chaparro, \& He, 2017). It is much slower than desktop keyboard typing speed, which is around $60 \mathrm{wpm}$ (Salthouse, 1984). Physical mobile keyboards (MacKenzie \& Soukoreff, 2002a) do exist but are not as common as touchscreen virtual keyboards, so physical mobile keyboards are not the focus of the current study. 
In order to cover the unique characteristics of mobile touchscreen typing, previous models need to be revised. Holleis et al. (2007) extended KLM and adjusted operator time values for mobile phone interaction with a standard physical number keypad. As the original KLM method, it assumed the same fixed time value for all keystrokes. This simple assumption, however, omitted the effect of finger moving distance on keystroke time that has been well established by Fitts' Law (Fitts, 1954). Previous phone number dialing models (number keypad dialing) in ACT-R also used a fixed value (e.g., $210 \mathrm{~ms}$ ) for each digit keystroke movement on the keypad (Salvucci, 2005). Such simplification is less suitable for modeling mobile touchscreen sentence typing due to the variety of virtual keyboards. A more accurate assumption is to estimate individual tapping time using Fitts' Law. QN-ACTR, as well as ACT-R, has used Fitts' Law in the estimation of keystroke time, but the previous assumptions (all finger typing without visual attention on the keys) were designed for desktop keyboard typing. The assumptions need to be modified for mobile touchscreen typing.

The goal of the current study is to build and validate a model for mobile phone touchscreen typing using QN-ACTR, with revised assumptions that are different from the ones used in previous desktop keyboard typing models. Theoretically, it is a further examination of QN-ACTR cognitive architecture, which aims to explain and model human performance in a wide range of tasks. For design practice, this work could provide a more accurate model of touchscreen typing, which could be used to evaluate interface and predict task completion time. In addition, after the typing task is modeled, future studies can combine the model with driving performance models for the analysis of dualtask performance while driving, which is important for driving safety research and 
design. In the current study, we built the typing model and examined it by comparing its results with human results collected from the same typing tasks. In particular, we analyzed the effect of finger movement distance on typing time performance. This effect could not be simulated by previous models that used a fixed time value for all keystrokes. The methods and results are described in the following sections for the two experiments respectively. Experiment 1 built the model and focused on a number typing task, whereas Experiment 2 validated the model on a sentence typing task.

\section{EXPERIMENT 1: NUMBER TYPING TASK}

\section{METHOD}

Human study. The human data used in Experiment 1 were from a previous study (He et al., 2014). We added new analysis of interkey time (i.e., interkey interval), providing a more detailed account of typing performance. The task was a number typing (digit entry) task. In each trial, a random 10-digit telephone number (grouped into three, three, and four digits, for example, "520-025-1314") was shown, and the participants were instructed to repeat the same number using the virtual keyboard and then tap the Send button. Similar tasks have been used in other studies (Horrey \& Wickens, 2004; Reed \& Green, 1999). A 4.3-inch HTC ThunderBolt touchscreen smartphone running the Android 2.3.4 operating system was used. The keys on the virtual keyboard were arranged in a QWERTY layout. Each number key has a height of about $7.4 \mathrm{~mm}$ and a width of about $4.5 \mathrm{~mm}$. Figure 1 shows the interface. 


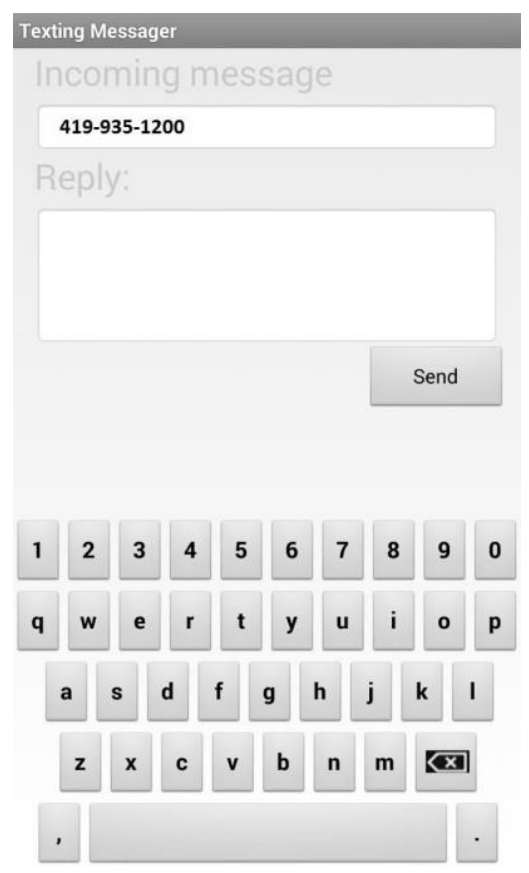

Figure 1. Screenshot of the experiment interface displaying a random 10-digit number.

The analysis focused on interkey time and the effects of digit position and interkey distance on interkey time. Interkey time is the time interval from the previous key press to the current key press (Salthouse, 1984). Digit position refers to the order of keys typed in each trial. For example, in the trial illustrated in Figure 1 (with a 10-digit number 419935-1200), the first key (i.e., digit position =1) is 4, and the fifth key (i.e., digit position $=5$ ) is 3 . Interkey distance refers to the distance between the previous key and the current key, measured in the unit of Adjacent-key Horizontal Distance (AHD). AHD is the horizontal distance between the centers of two adjacent number keys. For example, the interkey distance between Key 2 and Key 0 is 8 AHD (Figure 1). An advantage of using AHD as the unit, rather than pixel or millimeter, is that AHD provides a common measure for different mobile devices with various sizes and resolutions.

Thirty-five participants ( 11 men and 24 women, mean age $=22$ years, $S D=4$ years) from the community of Wichita State University volunteered to participate in this study. 
They all had normal or corrected-to-normal vision ability and reported sending 102 text messages on average per day $(S D=111)$. After signing the consent form, each participant practiced for about 2 minutes to get familiar with the interface. Then the formal typing test lasted about 12 minutes.

Modeling and simulation. As we mentioned in the introduction, previous typing models in QN-ACTR were able to simulate desktop keyboard typing performance (Cao \& Liu, 2013). For example, when typing letter "r", a model needs to move the index finger of the left hand from its resting position (Key f) to the target (Key r), press the key, and move the finger back to the resting position on the desktop keyboard, without the aid of visual attention. The motor module prepares, initiates, and executes each finger movement. The processing time for each motor stage is calculated following the methods of Executive-Process Interactive Control (EPIC) (Kieras \& Meyer, 1997), which have been adapted to ACT-R (Byrne \& Anderson, 1998) and QN-ACTR. Further adapting previous models to mobile touchscreen typing, we proposed the following assumptions.

- Assumption 1 (digit grouping): the model reads the 10-digit number by groups of three, three, and four digits ( $\mathrm{xxx}-\mathrm{xxx}-\mathrm{xxxx})$. It is the common style for phone numbers in North America. This assumption has also been used in previous studies (Salvucci, 2005). In this way, the model will read one group of digits, type these digits, and then continue reading the next group of digits.

- Assumption 2 (looking at keys): the model needs to visually attend the location of the target key before it moves the finger to the key. Since the virtual keys on the touchscreen are small in size and provide no tactile feedback, users need to look at each key before tapping. 
- Assumption 3 (thumb typing): the model types on the touchscreen (portrait orientation) with one hand and uses only the thumb finger. The previous human study (He et al., 2014) did not report which hand and finger were used, so later in Experiment 2 of the current study, we repeated the number typing task and explicitly instructed the participants to type with one hand and the thumb finger. The current work focused on portrait phone orientation and one hand typing.

We initially built the model with only the above three assumptions; however, the model could not reproduce all the human typing results, which will be shown later in the results section. After observing how people typed, we added another assumption.

- Assumption 4 (homing action): after typing each group of keys, the model returns the finger to a natural resting/home position. Similar homing actions were used in previous KLM models (Card et al., 1980). The difference is that in the current model for touchscreen typing, the home position is above the screen surface, which means that the finger stops in the air and does not touch the touch-sensitive screen in this resting position. From our observation of participants typing, the resting position was around Key 5, so the area above the surface of Key 5 was used as the resting position in the current model. In the results section, we will present the modeling results with this assumption in comparison to the results without it, demonstrating that it is needed to fully explain human data.

Implementing these assumptions, a model was built in QN-ACTR to simulate the human performance (source codes are available at https://github.com/HOMlab/QN- 
ACTR-Release). Using QN-ACTR's task template (Cao \& Liu, 2012), the typing interface was defined in the model with a screen layout and button sizes identical to the ones from the human study. Task-specific knowledge was defined as a series of production rules, each of which represents a step in the task procedure (Table 1). The production rules were defined following previous ACT-R and QN-ACTR models for human-computer interaction and desktop keyboard typing. The procedure for each trial was to first read every digit within a group of digits (three or four digits per group), then move the finger and tap each number key with the assistance of visual attention, and repeat the previous steps for the next group of digits until the whole number was typed. Finally, the model moved the finger to the Send key and tapped it. In particular, the model's procedure was to visually attend individual digit rather than perceiving three or four digits as a chunk, because the digits were randomly generated for each trial and unlikely to form chunks. Using simulation, we confirmed that if the random digits were perceived in chunks, the interkey time would become too short (around $500 \mathrm{~ms}$ shorter than human results) due to the time reduced from not visually attending and encoding individual digits. 
Table 1. Production rules for the mobile touchscreen number typing task.

\begin{tabular}{|c|c|}
\hline Production rule name & $\begin{array}{c}\text { Task procedure (description of the source code) } \\
\end{array}$ \\
\hline create-imaginal-chunk & $\begin{array}{l}\text { Create a mental representation for the temporary storage of a group } \\
\text { of digits to be typed. }\end{array}$ \\
\hline find-unattended-digit & Find the visual location of the next digit. \\
\hline attend-digit & Visually attend the digit. \\
\hline $\begin{array}{l}\text { encode-digit-d1, } \mathrm{d} 2, \mathrm{~d} 3 \text {, } \\
\text { or } \mathrm{d} 4 \text { (for each digit in a } \\
\text { group, four rules total) }\end{array}$ & Visually encode the digit and store it in the mental representation. \\
\hline $\begin{array}{l}\text { typing-digit-start-d1, d2, } \\
\mathrm{d} 3 \text {, or } \mathrm{d} 4 \text { (for each digit } \\
\text { in a group, four rules } \\
\text { total) }\end{array}$ & $\begin{array}{l}\text { After all digits in a group have been encoded, start to type each } \\
\text { digit as stored in the mental representation. }\end{array}$ \\
\hline $\begin{array}{l}\text { find-key-0 9, or Send } \\
\text { (11 rules total) }\end{array}$ & Find the visual location of the next key to be tapped. \\
\hline $\begin{array}{l}\text { attend-key-and-move- } \\
\text { finger }\end{array}$ & $\begin{array}{l}\text { Visually attend the key and move the thumb finger to the key } \\
\text { location. }\end{array}$ \\
\hline tap & Tap the key. \\
\hline $\begin{array}{l}\text { type-next-digit-d2, } \mathrm{d} 3, \text { or } \\
\mathrm{d} 4 \text { (for each digit in a } \\
\text { group, three rules total) }\end{array}$ & $\begin{array}{l}\text { Take a note in the mental representation of the just tapped digit and } \\
\text { start to type the next digit in the group. }\end{array}$ \\
\hline read-next-digit-group & $\begin{array}{l}\text { After all digits in a group have been typed, move finger to resting } \\
\text { position and start to read the next digit group. (The procedure will } \\
\text { go back to find-unattended-digit.) }\end{array}$ \\
\hline tap-send & After all groups have been typed, start to tap the Send key. \\
\hline trial-done & After tapping the Send key, stop. \\
\hline
\end{tabular}

Except for Assumption 3 (thumb typing), all other assumptions were implemented in the production rules (as listed in Table 1). Assumption 3 (thumb typing) was implemented in the motor module by adding two motor commands (i.e., move-handtouch and tap) adapted from a recent ACT-R extension called ACT-Touch (Greene \& Tamborello, 2013). ACT-Touch extended the motor commands of ACT-R as well as QNACTR for touchscreen tapping. In particular, move-hand-touch was used in the current model to move the thumb. The movement time is governed by Fitts' Law.

In particular, the equation used is

$$
T=b^{*} \log _{2}(D / W+0.5)
$$


where $T$ is the time of the movement in seconds; $b$ is a parameter with value 0.1

(Greene \& Tamborello, 2013); $D$ is the distance to the target; $W$ is the width of the target.

The tap motor command is analogous to ACT-R's punch movement style. That is, a finger moves towards a target location on the touchscreen, touches that location, and then returns to its initial position. The physical movement time is also governed by Fitts' Law applied along the $\mathrm{z}$-axis, that is, the direction perpendicular to the touchscreen surface. Previous work of ACT-Touch focused on tapping distance error (Greene \& Gallagher, 2014), whereas the current study focused on time performance.

In the current study, all model parameters were set at their default values. For example, a visual attention shift will take $85 \mathrm{~ms}$ by default; a production rule execution will take $50 \mathrm{~ms}$ by default. No parameter values were adjusted to fit the human data. Each simulation run contained 80 trials, same as the human study. In each trial, the model typed 10 numerical digits followed by the Send key, resulting in a total of 11 key presses (10 interkey time intervals). The simulation was repeated multiple times until the averaged results reached a steady state. The stopping criterion was that the widths of the 95\% confidence intervals for all interkey time measures are smaller than $50 \mathrm{~ms}$. In the end, 35 simulation runs were performed.

\section{RESULTS}

Human results. Overall, the participants' average interkey time was $591 \mathrm{~ms}$. The estimated typing speed was 20 words per minute (wpm), according to a commonly used estimation rule that "wpm is obtained by multiplying characters per second by 60 (seconds per minute) and dividing by 5 (characters per word)" (MacKenzie \& Soukoreff, 2002b). Figure 2 (Human Experiment 1) shows the averaged results from all participants. 
There were a total of 10 digits typed as well as the final Send key. In the case of digit position 1, the time interval from the trial onset to the first digit tap was used as the time value.

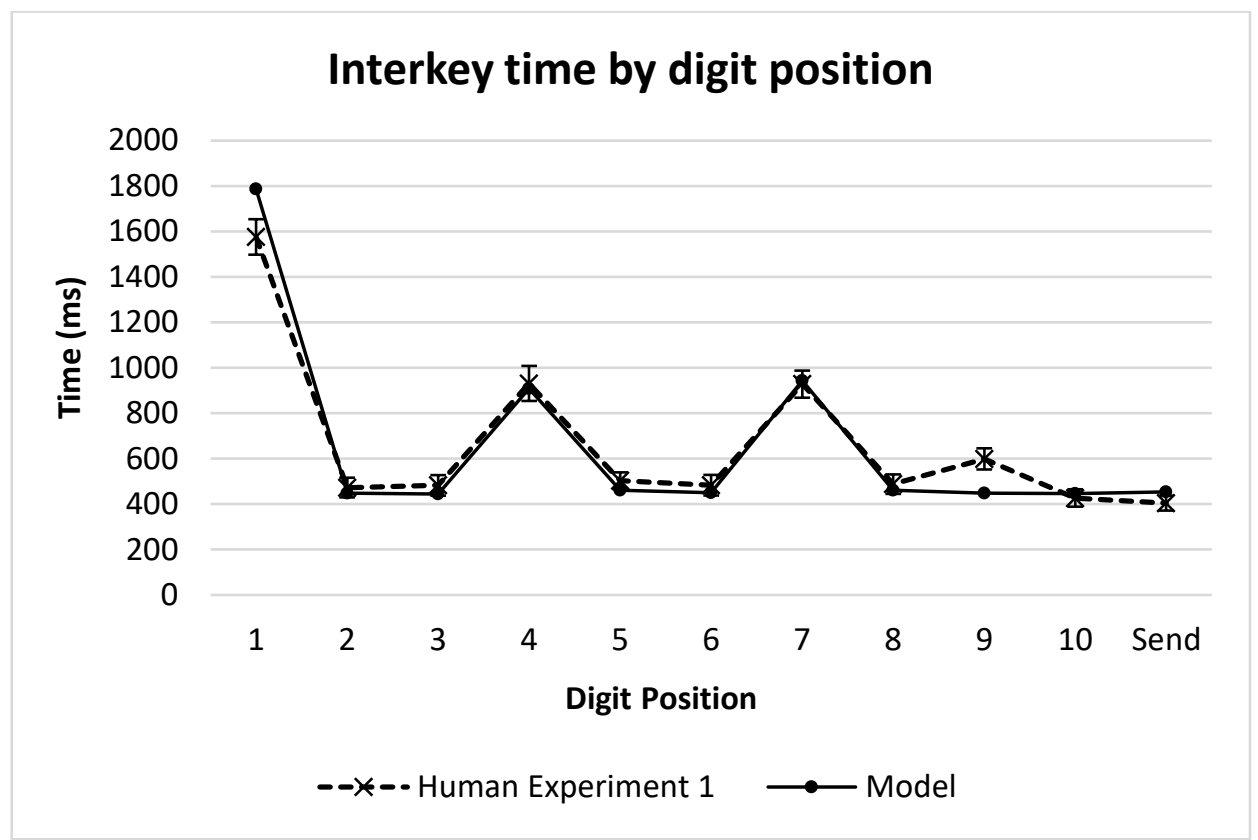

Figure 2. Effect of digit position on interkey time for both human study Experiment 1 and model results. Note: in the case of digit position 1, the time interval from the trial onset to the first digit tap was used as the time value. Error bars represent $95 \%$ confidence intervals of the human data.

Repeated measures ANOVA was conducted using SPSS (version 21) to test the effect of digit position on interkey time. One sample was excluded due to missing data. The results $(N=34)$ revealed a significant effect of digit position, $F(10,330)=354.226, p<$ $.001, \eta^{2}=0.915$. Pairwise comparisons were also conducted (with Bonferroni correction, significance level at 0.05 ). Time value of the first key tap (digit position 1) was significantly longer than all other time values by $1010 \mathrm{~ms}$ on average; interkey time values at digit position 4 and 7 (i.e., leading digits of the second and the third digit 
groups) were not significantly different, but both of them were significantly longer than the values at digit position 2, 3, 5, 6, 8, 9, and 10 (i.e., following digits in each digit group) as well as the value for the Send key by $440 \mathrm{~ms}$ on average; the time value at digit position 9 was significantly longer than the values from other following digits and the Send key by $140 \mathrm{~ms}$ on average; the time value at digit position 10 was significantly shorter than digit position 5 by $75 \mathrm{~ms}$.

The above analysis revealed that interkey time values at the leading digits (position 4 and 7) were significantly longer than the values at the following digits (position 2, 3, 5, 6, 8,9 , and 10). Thus, the next analysis about the effect of interkey distance on interkey time was separated into two groups, depending on the pressed key, either a leading or following digit in a group of digits.

Repeated measures ANOVA was conducted to test the effects of interkey distance on interkey time for the leading and following digits separately. Because of randomness in the number shown for each trial, not every participant had all the interkey distance conditions, so only part of the samples $(N=11)$ were included in this analysis. For the leading digits, the effect of interkey distance on interkey time was not significant, $F(9$, $90)=0.808, p=.610, \eta^{2}=0.075$ (Figure 3 Human Experiment 1). Since ANOVA would remove all the data points from a participant if any missing data point was found, a lot of data were excluded in this case. In order to include more data points in the analysis, an additional statistical analysis was conducted using Mixed Model (SPSS version 21). Again, the effect of interkey distance on interkey time was found to be not significant, $F(9,22.1)=1.098, p=.404$. 


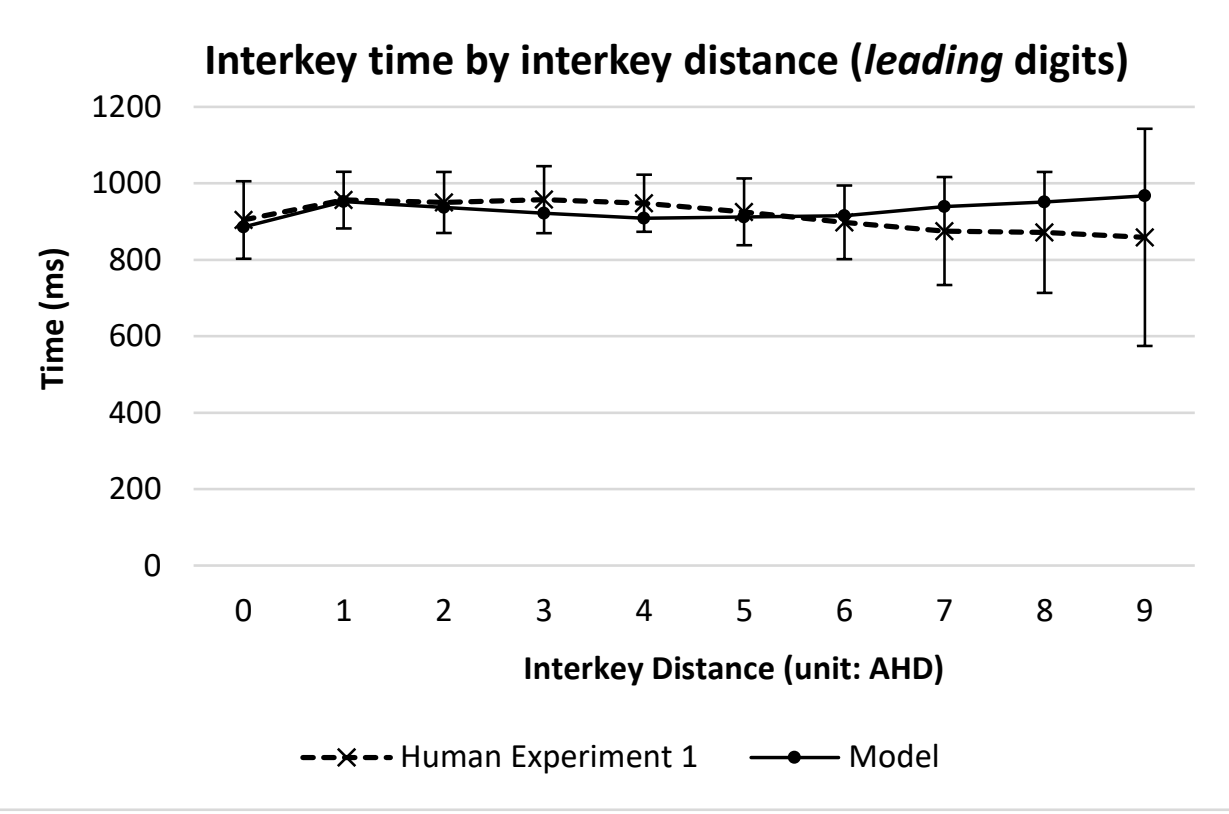

Figure 3. Effect of interkey distance on interkey time of the leading digits (position 4 and 7) for both human study Experiment 1 and model results. Note: zero interkey distance means the previous key and the current key are the same. AHD: Adjacent-key Horizontal Distance. Error bars represent $95 \%$ confidence intervals of the human data from Experiment 1.

In contrast, for the following digits of a digit group, the effect of interkey distance on interkey time was significant $(N=32), F(9,279)=24.647, p<.001, \eta^{2}=0.443$ (Figure 4 Human Experiment 1). Pairwise comparisons (with Bonferroni correction, significance level at 0.05 ) showed that the interkey time significantly increased for each step of interkey distance increment from distance 0 to 3 AHD. 


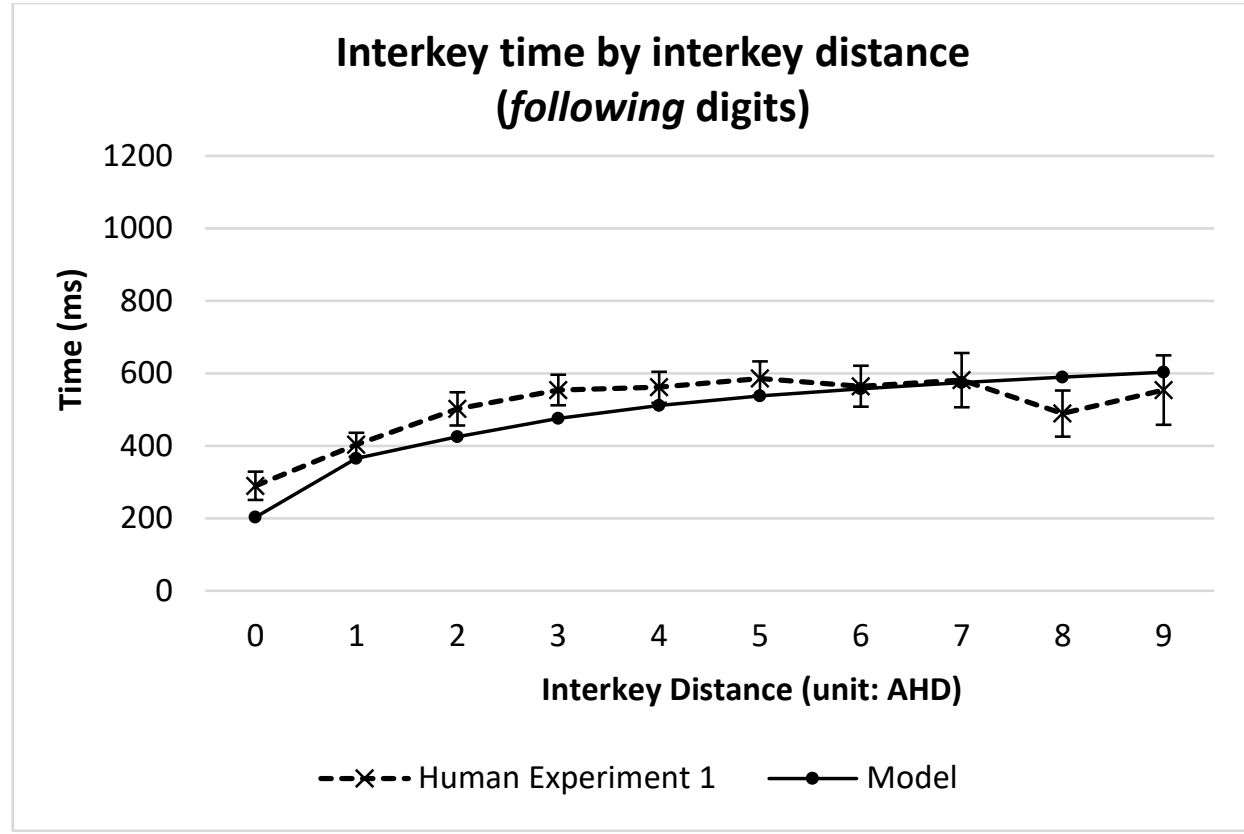

Figure 4. Effect of interkey distance on interkey time of the following digits (position 2, 3, 5, 6, 8, 9, and 10) for both human study Experiment 1 and model results. Note: zero interkey distance means the previous key and the current key are the same. AHD: Adjacent-key Horizontal Distance. Error bars represent 95\% confidence intervals of the human data from Experiment 1.

Modeling results. Overall, the model's average interkey time was $557 \mathrm{~ms}$, which translates to an estimated typing speed of $22 \mathrm{wpm}$. This is similar to the human results (591 ms and $20 \mathrm{wpm}$ ). The modeling results from each test condition were plotted and compared with the human results in Figure 2, Figure 3, and Figure 4. Overall, in comparison to the human results, the model results had a root-mean-square error (RMSE) of $65 \mathrm{~ms}$.

We examined the necessity of Assumption 4 (homing action) by testing an alternative model with only Assumption 4 removed. The alternative model's fitness was only 
affected in the case of the leading digits, as shown in Figure 5. The RMSE increased to $176 \mathrm{~ms}$.

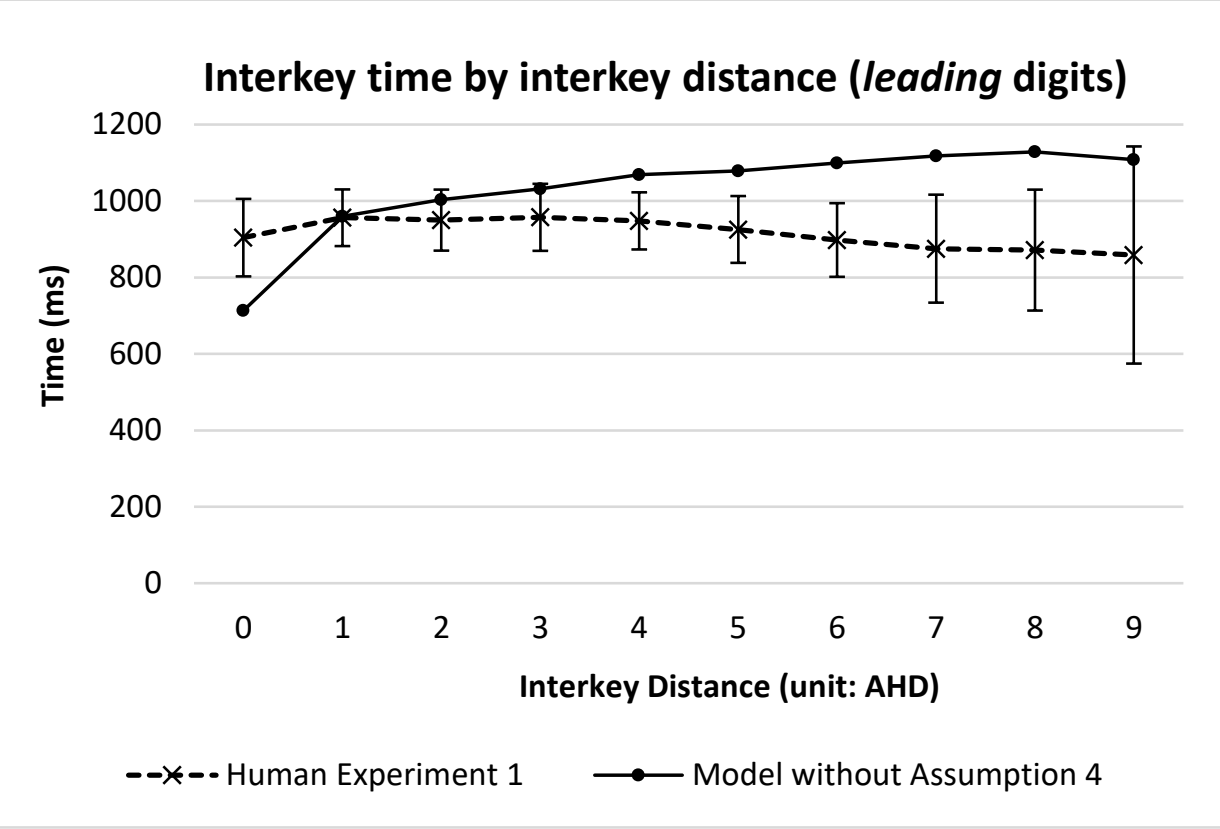

Figure 5. Effect of interkey distance on interkey time of the leading digits (position 4 and 7) for both human study Experiment 1 and the alternative model (without Assumption 4, homing action) results. AHD: Adjacent-key Horizontal Distance. Error bars represent $95 \%$ confidence intervals of the human data from Experiment 1.

\section{DISCUSSION OF EXPERIMENT 1}

To understand the effect of Assumption 4 (homing action), it is important to know that the impact of removing the assumption depends on the interkey distance. To explain this effect, let us name the digits by its position as ABC-DEF-GHIJ (each letter represents a digit) and take a closer look at the interkey time between Key $\mathrm{C}$ (the third key) and Key D (the fourth key). After adding Assumption 4, the finger movement from Key C to Key D is divided into two parts, first, from Key C to Key 5, and second, from Key 5 to Key D. Note that the first movement happens in parallel with the process of 
reading the next digit group (as described in the production rule read-next-digit-group in Table 1), so it has little impact on interkey time. The second movement, however, is critical and will affect the interkey time. The change in time can be understood by analyzing the change in distance. An extreme case is when the interkey distance between Key $\mathrm{C}$ and $\mathrm{D}$ is zero (i.e., they are the same number), adding Assumption 4 will most likely to increase critical distance and time (unless Key C and D happens to be Key 5). Therefore, removing Assumption 4 speeds up the model in this case (Figure 5, when interkey distance $=0$ ). In another extreme case, when interkey distance between Key $\mathrm{C}$ and D is 9 (i.e., they are the left-most Key 1 and the right-most Key 0), adding Assumption 4 reduces time, because the critical distance is reduced by around half. As a result, removing Assumption 4 slows down the model in this case (Figure 5, when interkey distance $=9$ ). When the interkey distance is between 0 and 9 , the results will be a mix. As the interkey distance becomes longer, Key 5's location is more likely to be between Key C and D, so adding Assumption 4 is more likely to reduce time. In conclusion, the analysis confirmed that Assumption 4 (homing action) is necessary.

\section{EXPERIMENT 2: SENTENCE TYPING}

\section{METHOD}

Modeling and simulation. The goal of Experiment 2 is to validate the QN-ACTR mobile touchscreen typing model, examining its predictive capability of simulating sentence typing time performance. To allow the typing of sentences rather than digits, we adapted the model from Experiment 1 with two adjustments. 
First, Assumption 1 (digit grouping) was changed to accommodate word reading. The revised Assumption 1' (word grouping) assumes that the model reads a group of words, types them, and then reads the next group of words. The number of words in each group is referred to as copying span, defined as the amount of material that can be typed accurately after a single inspection of the copy (Salthouse, 1985; Wu \& Liu, 2008). This value of copying span is around two to eight words as suggested by Salthouse (1986). In the current study, we tried different values between two to eight and found that it mainly affected the delay of the first keystroke in a sentence. After comparing model results with the human data, as a post hoc decision, we used the value of two as the copying span in the model, which produced the modeling results closest to the human data. All other assumptions in Experiment 1 were not changed.

Second, the production rules used in the number typing model (Experiment 1) were revised to accommodate letter typing. This adjustment was mainly about changing the mental representation from digits to words and letters. The production rules about finding keys and moving fingers were not changed. The production rules used in Experiment 2 are listed in Table 2. 
Table 2. Production rules for the mobile touchscreen sentence typing task.

\begin{tabular}{ll}
\hline \multicolumn{1}{c}{ Production rule name } & \multicolumn{1}{c}{ Task procedure (description of the source code) } \\
\hline create-imaginal-chunk & $\begin{array}{l}\text { Create a mental representation for the temporary storage of a } \\
\text { sentence to be typed. }\end{array}$ \\
\hline find-unattended-word & Find the visual location of the next word. \\
\hline attend-word & Visually attend the word. \\
\hline $\begin{array}{l}\text { encode-word1, encode- } \\
\text { word2 (up to two words } \\
\text { each round) }\end{array}$ & $\begin{array}{l}\text { Visually encode the word and store it in the mental representation. } \\
\text { When all words in this round are encoded, change state to respond. }\end{array}$ \\
\hline all-encoded & $\begin{array}{l}\text { If all words in the sentence have been encoded, change state to } \\
\text { respond. }\end{array}$ \\
\hline typing-letter-start & $\begin{array}{l}\text { When state is respond, start to type each letter or space as stored in } \\
\text { the mental representation. }\end{array}$ \\
\hline $\begin{array}{l}\text { find-key-0 9*, a Z, } \\
\text { Space, or Send (38 rules } \\
\text { total) }\end{array}$ & $\begin{array}{l}\text { Find the visual location of the next key to be tapped. } \\
\text { attend-key-and-move- } \\
\text { finger* }\end{array}$ \\
\hline tap & $\begin{array}{l}\text { Visually attend the key and move the thumb finger to the key } \\
\text { location. }\end{array}$ \\
\hline read-next-word-group & $\begin{array}{l}\text { Tap the key. (When there is any remaining item in the group, the } \\
\text { procedure will go back to typing-letter-start.) }\end{array}$ \\
$\begin{array}{l}\text { After all items in a group have been typed, move finger to resting } \\
\text { position and start to read the next group. (The procedure will go } \\
\text { back to find-unattended-word.) }\end{array}$ \\
\hline After the whole sentence has been typed, start to tap the Send key. \\
\hline trial-dond & After tapping the Send key, stop. \\
\hline *: production rules that are identical to the ones used in Experiment 1 model.
\end{tabular}

Human study. We conducted an empirical study to collect touchscreen sentence typing data for model validation. The typing materials are short sentences (500 in the pool) adapted from previous studies (MacKenzie \& Zhang, 1999). All sentences (or phrases) are in English and consist of common words, for example, "all work and no play" and "love means many things" (without period mark). The number of words in a sentence ranges from 3 to 9 (mean $=5.4, S D=1.1$ ). The number of characters (with spaces) in a sentence ranges from 16 to 43 (mean $=28.6, S D=5.0$ ). Overall, the number of characters in a word ranges from 1 to 13 (mean $=4.5, S D=2.4$ ). In each trial, the task 
was to type the sentence using the virtual keyboard and then tap the Send button. After the participants hit the Send button, the next trial appeared immediately.

The device was a 5-inch Samsung Galaxy S4 touchscreen smartphone running the Android 5.0.1 operating system. Although the 5-inch screen was larger than the 4.3-inch one in Experiment 1, the keyboard layout and key size used in the testing program were the same as the ones used in Experiment 1. We also repeated the same number typing task and expected the results to be the same as in Experiment 1. For each participant, there were 80 trials in the number typing task and 80 trials in the sentence typing task.

Fourteen students (seven males and seven females) from University of Waterloo participated in the study. Their age ranged from 18 to 25 years ( $m e a n=21, S D=2$ ). They all had normal or corrected-to-normal vision. All participants owned a touchscreen smartphone and reported sending about 101 text messages on average every day $(S D=$ 47). They were compensated with ten dollars for this one-hour study.

Upon arrival, participants completed a formal consent form and a demographical questionnaire about their age and text message habits. Next, participants were provided with a detailed pre-study information package and an explanation of the study. They were instructed to type with one hand and aim for both entry speed and accuracy as they normally would. However, if mistyped any letter, they were instructed to continue without correcting it, because the current study focused on typing time performance. Participants completed a brief practice session to familiarize themselves with the tasks before the formal test. Each participant completed both sentence typing and number typing tasks. The order of experiencing the two tasks was counter-balanced. A twominute break was given between the two tasks. 


\section{RESULTS}

Data from four participants were excluded due to technical error and missing data. Data from 10 participants were included in the analysis. All participants typed with only one hand and used the thumb finger. From the number typing task, interkey time values were calculated and compared to the results from Experiment 1 (as shown in Figure 6, Figure 7, and Figure 8). Similar to the statistical analyses used in Experiment 1, repeated measures ANOVA and Mixed Model (to consider missing data) analyses were conducted using SPSS (version 21), with experiment number (1 vs. 2) added as a between-subject factor. The goal is to check if there is any significant difference between Experiment 1 and 2. The results showed no significant difference between Experiment 1 and 2 for all the analyses ( $p$ values $\geq .160$ ), and there was also no significant interaction between experiment number and digit position or interkey distance ( $p$ values $\geq .462$ ). Overall, the differences in the interkey time from all conditions between Experiment 1 and 2 had an $R M S E$ value of $68 \mathrm{~ms}$. This confirmed that the results from Experiment 2 were comparable to the ones from Experiment 1. 


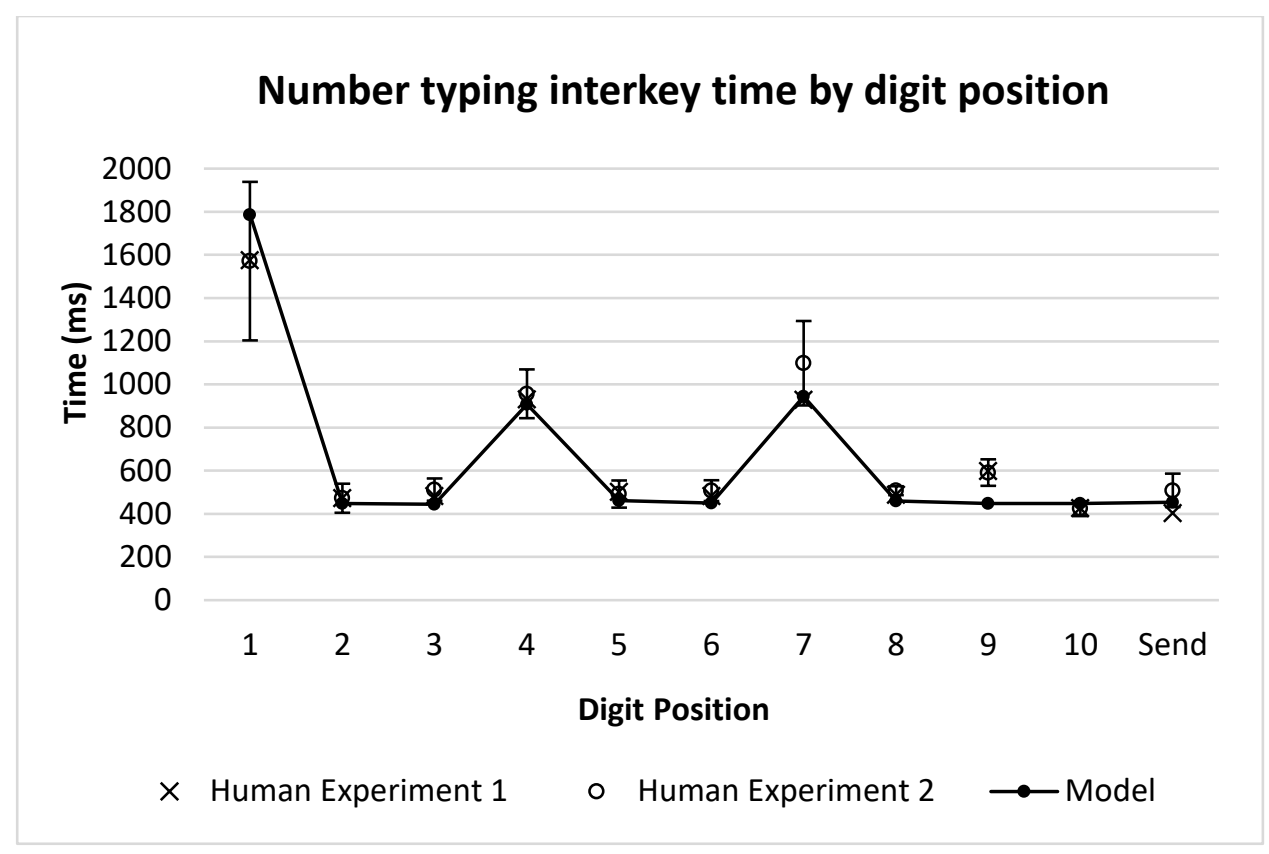

Figure 6. Effect of digit position on number typing interkey time for human study Experiment 1, Experiment 2, and model results. Note: in the case of digit position 1, the time interval from the trial onset to the first digit tap was used as the time value. Error bars represent 95\% confidence intervals of the human data in Experiment 2. 


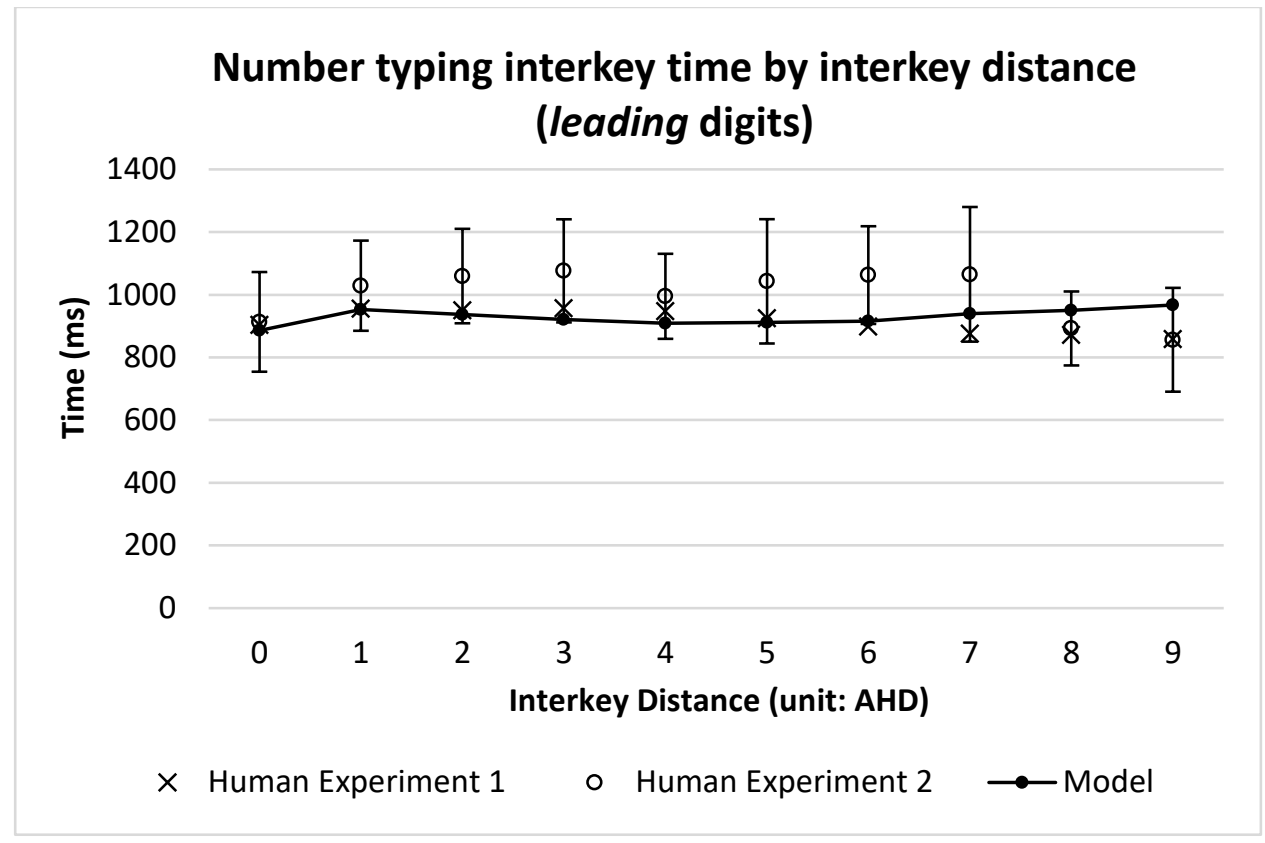

Figure 7. Effect of interkey distance on number typing interkey time of the leading digits (position 4 and 7) for human study Experiment 1, Experiment 2, and model results. Note: zero interkey distance means the previous key and the current key are the same. AHD: Adjacent-key Horizontal Distance. Error bars represent 95\% confidence intervals of the human data in Experiment 2. 


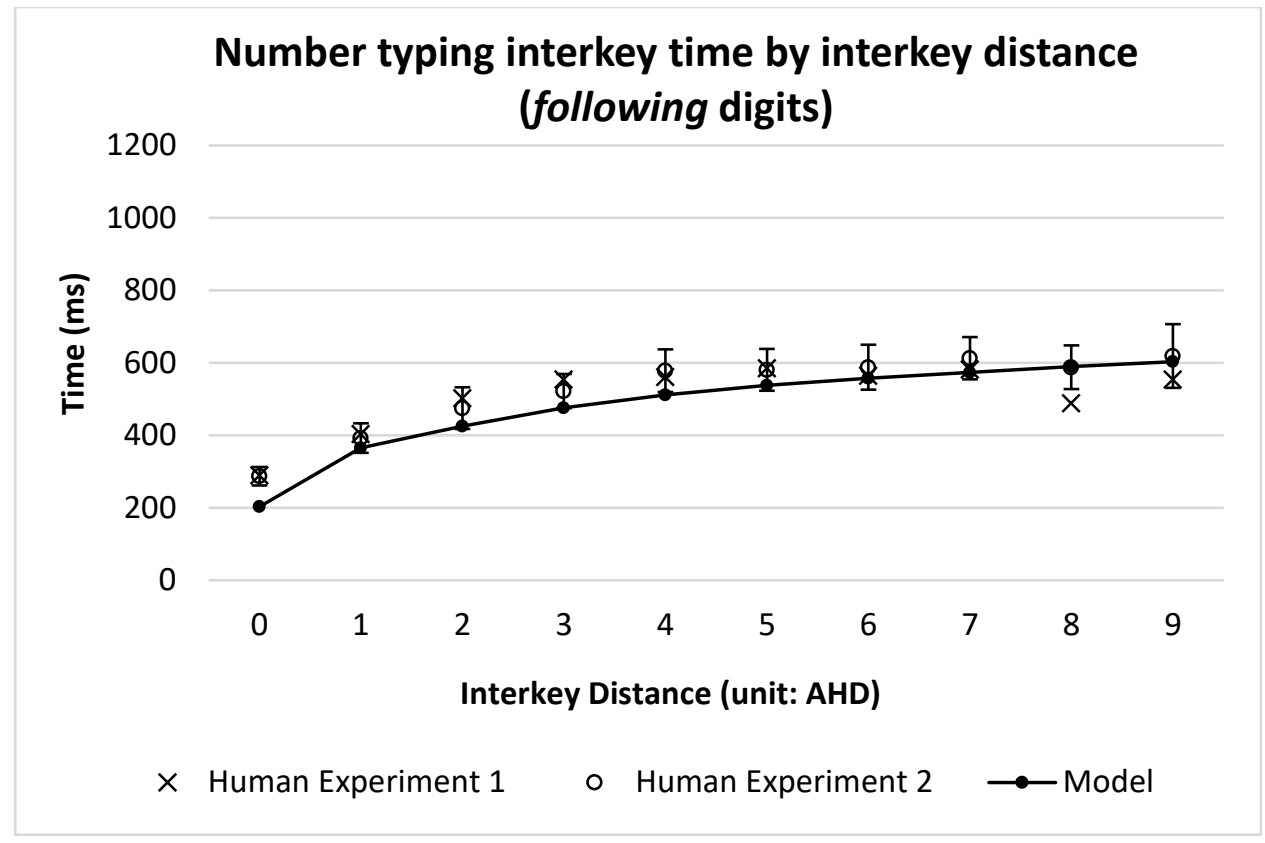

Figure 8. Effect of interkey distance on number typing interkey time of the following digits (position 2, 3, 5, 6, 8, 9, and 10) for human study Experiment 1, Experiment 2, and model results. Note: zero interkey distance means the previous key and the current key are the same. AHD: Adjacent-key Horizontal Distance. Error bars represent 95\% confidence intervals of the human data in Experiment 2.

For the sentence typing task, the modeling results were averaged from 5 simulation runs, reaching a criterion that the widths of the $95 \%$ confidence intervals for all interkey time measures were smaller than $50 \mathrm{~ms}$. This model required fewer simulation runs to reach steady results than it did in Experiment 1, because here each sentence had more characters than the number of digits in Experiment 1, and more interkey time samples can be collected from each trial in Experiment 2.

Overall, the model for touchscreen sentence typing produced interkey time prediction as $442 \mathrm{~ms}$, which meant 27 wpm. The human interkey time was $367 \mathrm{~ms}$ (which meant 33 wpm). We also conducted detailed analyses regarding the effects of letter position and 
interkey distance on interkey time, in a way similar to the analyses in Experiment 1. Letter position refers to the order of letters typed in each word. Two cases were considered for the first letter of a word, either the first letter of a sentence, or the first letter of other words. In addition, interkey time values for the Space key and the Send key were also analyzed. The results from both human and model are plotted and compared in Figure 9. The amount of interkey time raw data points from each participant on average was listed in Table 3. The RMSE between human and model results was $93 \mathrm{~ms}$.

Repeated measures ANOVA was conducted using SPSS (version 21) to test the effect of letter position on interkey time from the human data. The results $(N=10)$ revealed a significant effect of letter position, $F(12,108)=41.449, p<.001, \eta^{2}=0.822$. Pairwise comparisons were also conducted (with Bonferroni correction, significance level at 0.05). The time value of the first keystroke in the sentence (sentence $1^{\text {st }}$ ) was significantly longer than all other time values except the Send keystroke. The comparison between sentence $1^{\text {st }}$ and Send reached a $p$ value of 0.058 . The time value of the Send keystroke was significantly longer than the time values from letter position 4 to 8 . There was no significant difference between other pairs. 


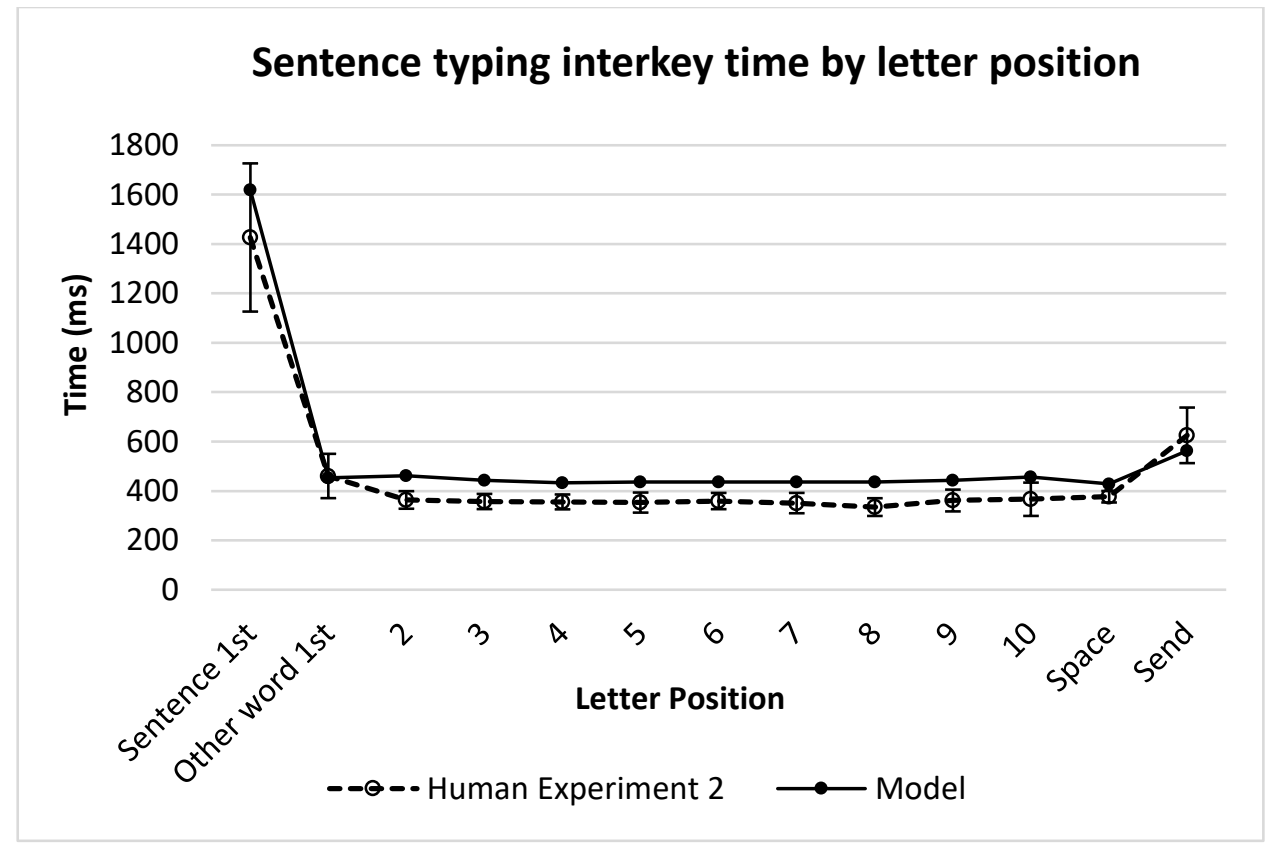

Figure 9. Effect of letter position on sentence typing interkey time for human study (Experiment 2) and model results. Note: for the first letter of a sentence, the time interval from the trial onset to the first letter tap was used as the time value. Error bars represent $95 \%$ confidence intervals of the human data.

Table 3. The amount of interkey time raw data points from a participant (mean count value \pm standard deviation) that was used to produce Figure 9.

\begin{tabular}{|c|c|c|c|c|c|c|c|}
\hline $\begin{array}{l}\text { Letter position } \\
\text { or key type }\end{array}$ & Sentence 1st & $\begin{array}{c}\text { Other word } \\
\text { 1st }\end{array}$ & 2 & 3 & 4 & 5 & 6 \\
\hline $\begin{array}{l}\text { Count of } \\
\text { data points }\end{array}$ & 80 & $320 \pm 41$ & $380 \pm 43$ & $313 \pm 38$ & $212 \pm 28$ & $142 \pm 19$ & $91 \pm 15$ \\
\hline $\begin{array}{l}\text { Letter position } \\
\text { or key type }\end{array}$ & 7 & 8 & 9 & 10 & Space & Send & \\
\hline $\begin{array}{l}\text { Count of } \\
\text { data points }\end{array}$ & $60 \pm 10$ & $39 \pm 7$ & $23 \pm 6$ & $11 \pm 5$ & $326 \pm 40$ & 80 & \\
\hline
\end{tabular}

The effects of interkey distance on interkey time were also analyzed for the first letter of a word (but not the first letter of a sentence) and the following letters of a word separately. In the first case, the key typed before the first letter (but not the first letter of a 
sentence) was always the Space key, so the analysis was about finger movement from the Space key to the letter keys. The results were plotted in Figure 10. The interkey distance was grouped into bins. For example, $(0,1]$ means $0<$ interkey distance $\leq 1$. The $R M S E$ between human and model results was $31 \mathrm{~ms}$. Regarding the effect of interkey distance on interkey time from the human data in this case, repeated measures ANOVA showed no significant difference, $F(2.0,18.1)=2.689, p=.095, \eta^{2}=0.230$ (degrees of freedom were corrected using Greenhouse-Geisser estimate of sphericity, because Mauchly's test indicated that the assumption of sphericity had been violated, $\chi^{2}(14)=35.412, p=.002$ ).

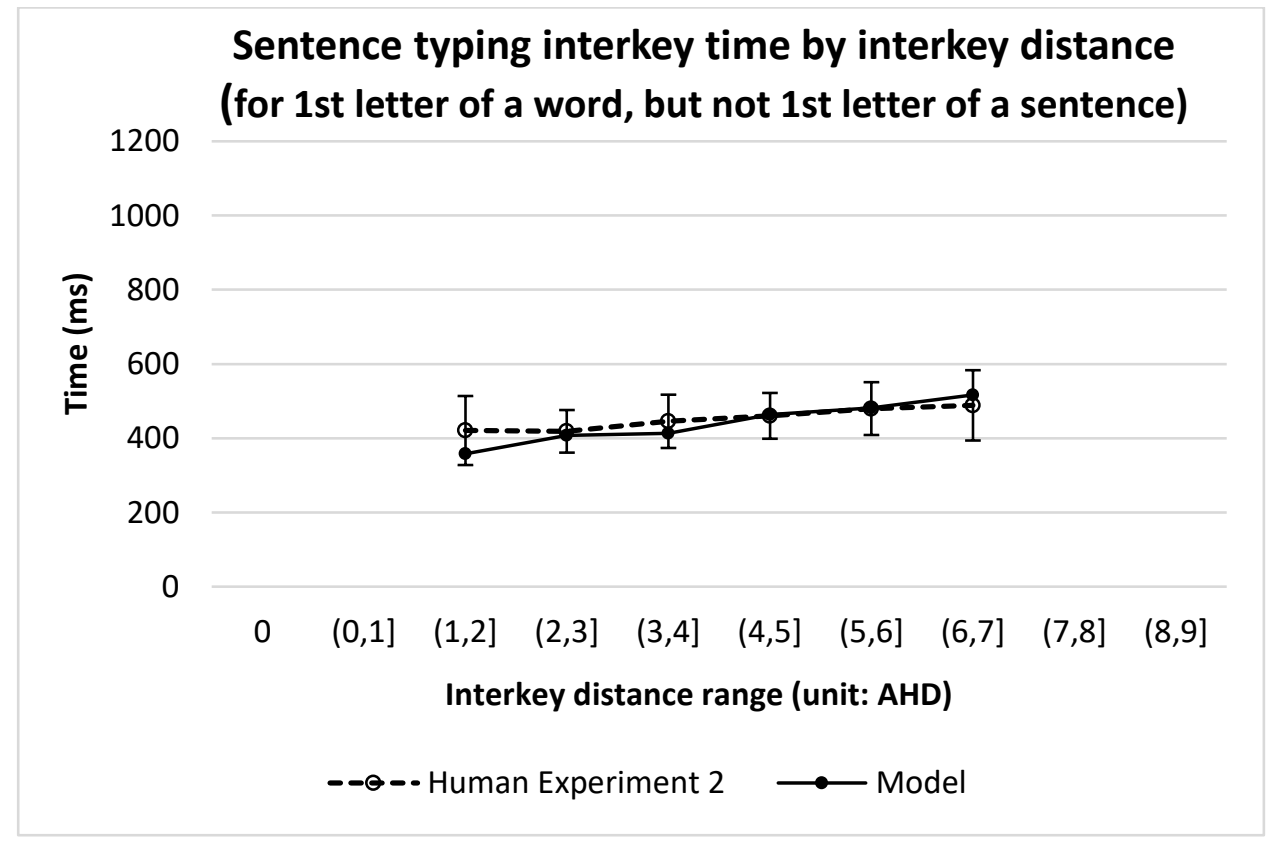

Figure 10. Effect of interkey distance on sentence typing interkey time of the first letter of a word (but not the first letter of a sentence) for human study (Experiment 2) and model results. AHD: Adjacent-key Horizontal Distance. $(0,1]$ means $0<$ interkey distance $\leq 1$. Error bars represent $95 \%$ confidence intervals of the human data. 
For the following letters of a word, the model results showed the trend of increasing interkey time with increasing interkey distance, same as the trend from the human data, as shown in Figure 11. The RMSE between human and model results was $84 \mathrm{~ms}$.

Regarding the effect of interkey distance on interkey time from the human data in this case, repeated measures ANOVA showed significant difference, $F(1.9,17.3)=34.485, p$ $<.001, \eta^{2}=0.793$ (degrees of freedom were corrected using Greenhouse-Geisser estimate of sphericity, because Mauchly's test indicated that the assumption of sphericity had been violated, $\chi^{2}(44)=113.181, p<.001$ ). Pairwise comparisons (with Bonferroni correction, significance level at 0.05 ) showed that the interkey time difference would be significant when the interkey distance difference was more than 2 AHD. 


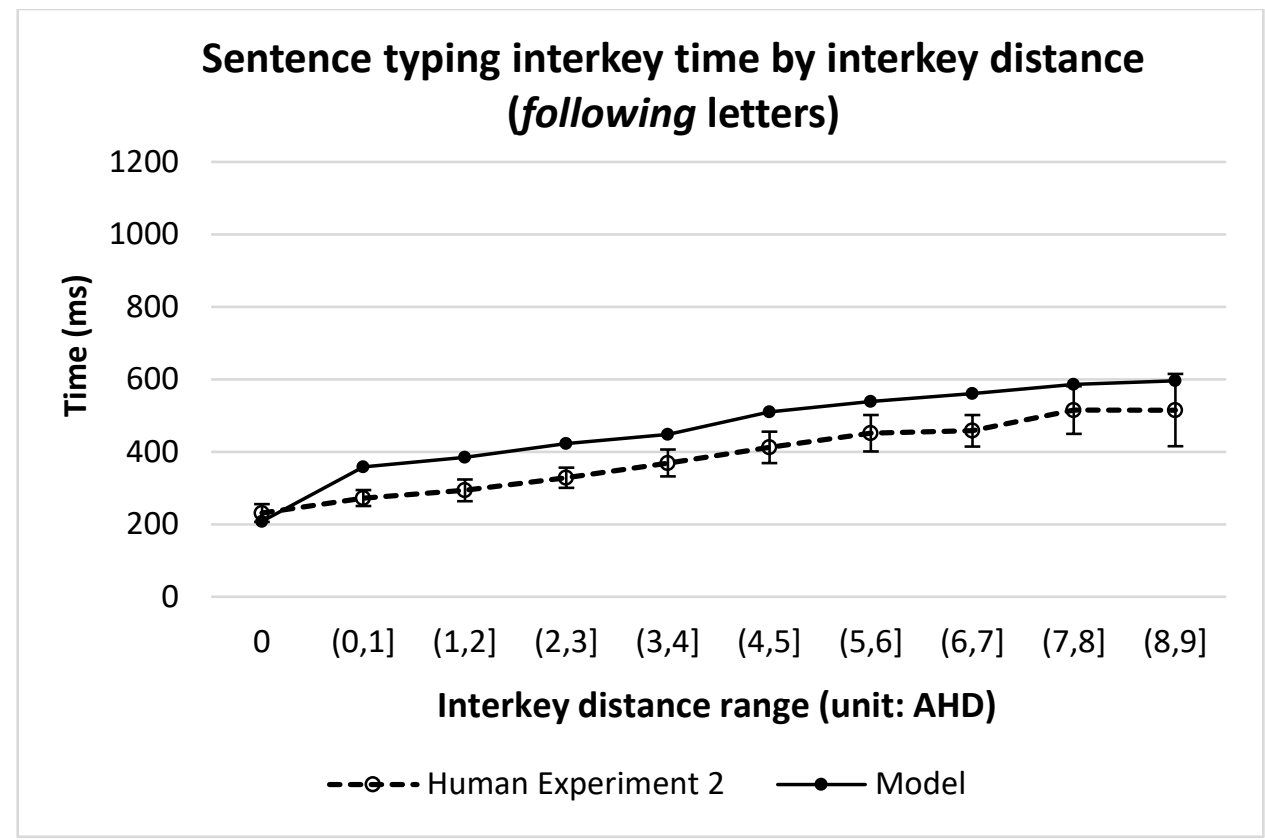

Figure 11. Effect of interkey distance on sentence typing interkey time of the following letters for human study (Experiment 2) and model results. Note: zero interkey distance means the previous key and the current key are the same. AHD: Adjacent-key Horizontal Distance. $(0,1]$ means $0<$ interkey distance $\leq 1$. Error bars represent $95 \%$ confidence intervals of the human data.

Although the focus of the current study is on modeling, it is interesting to compare human results from touchscreen typing with traditional keyboard typing results. In the typing literature, Salthouse (1986) reviewed 29 transcription typing phenomena or effects obtained from traditional keyboard typing. Among the 29 phenomena, we found that six were comparable to the results from the current study, one was not applicable, and the rest 22 were not tested in the current study. The one not applicable is about alternate-hand keystrokes. In the current study, typing was completed with only one hand and one thumb finger, so alternate-hand is not applicable. The 22 not tested ones are mainly about typing 
error and skill related effects, which are beyond the current study's scope. The six

comparable phenomena are listed in Table 4.

Table 4. Comparison of human typing behaviors using a traditional keyboard with

both hands and using a touchscreen virtual keyboard with only one hand and the thumb.

\begin{tabular}{|c|c|c|c|}
\hline ID & $\begin{array}{l}\text { Traditional keyboard typing with both } \\
\text { hands (Salthouse, 1986) }\end{array}$ & $\begin{array}{l}\text { Touchscreen virtual keyboard typing } \\
\text { with only one hand and the thumb } \\
\text { (current study human results) }\end{array}$ & Conclusion \\
\hline 1 & $\begin{array}{l}\text { Typing is faster than choice reaction time. } \\
\text { Choice reaction time was } 560 \mathrm{~ms} \text { on } \\
\text { average; in contrast, typing interkey time } \\
\text { was } 177 \mathrm{~ms} \text {. }\end{array}$ & Interkey time is $367 \mathrm{~ms}$ on average. & $\begin{array}{l}\text { One-thumb typing has much } \\
\text { longer interkey time. It becomes } \\
\text { closer to choice reaction time. }\end{array}$ \\
\hline 2 & $\begin{array}{l}\text { Typing is slower than reading. Typing } \\
\text { speed was } 58 \text { wpm. Reading speed was } \\
253 \text { wpm. }\end{array}$ & Typing speed is $33 \mathrm{wpm}$. & $\begin{array}{l}\text { One-thumb typing speed is much } \\
\text { slower than traditional keyboard } \\
\text { typing. It is also slower than } \\
\text { reading. }\end{array}$ \\
\hline 8 & $\begin{array}{l}\text { Digram frequency effect: digrams (letter } \\
\text { pairs) that occur more frequently in normal } \\
\text { language were typed faster than less } \\
\text { frequent ones. This effect was } \\
\text { demonstrated by contrasting a high- } \\
\text { frequency group to a low-frequency group } \\
\text { with comparable interkey distances. }\end{array}$ & $\begin{array}{l}\text { We conducted the analysis. The high- } \\
\text { frequency digrams included t-h, r-e, and } \\
\text { i-n, while the corresponding low } \\
\text { frequency ones included n-g, o-p, and } \\
\text { u-b. The high-frequency ones had } \\
\text { significantly shorter interkey time ( } p \\
\text { values < } 0.05 \text {; independent sample T } \\
\text { test). }\end{array}$ & $\begin{array}{l}\text { Digram frequency effect also } \\
\text { exists in one-thumb typing. }\end{array}$ \\
\hline 9 & $\begin{array}{l}\text { Interkey time is independent of word } \\
\text { length. }\end{array}$ & $\begin{array}{l}\text { Since the first letter in the sentence did } \\
\text { not have any previous key, it is not } \\
\text { considered for interkey time. Without } \\
\text { considering it, as shown in Figure } 9 \text {, } \\
\text { interkey time is very similar for letters } \\
\text { with different positions in a word (no } \\
\text { significant difference), so interkey time } \\
\text { should be independent of word length. }\end{array}$ & $\begin{array}{l}\text { It seems that this phenomenon } \\
\text { also exists in one-thumb typing. } \\
\text { The current study used one } \\
\text { sentence in each trial. Future } \\
\text { studies need to further examine } \\
\text { this phenomenon with multiple } \\
\text { sentences in each trial. }\end{array}$ \\
\hline 10 & $\begin{array}{l}\text { Word initiation effect: the first keystroke in } \\
\text { a word is slower than the subsequent } \\
\text { keystrokes. The interval before the first } \\
\text { keystroke in a word is approximately } 20 \% \\
\text { longer than that between the later } \\
\text { keystrokes in the word. }\end{array}$ & $\begin{array}{l}\text { There are two cases. In the first case, } \\
\text { for the first keystroke in a word that is } \\
\text { not the first word of the sentence, the } \\
\text { interval before it is } 29 \% \text { longer than } \\
\text { that between the later keystrokes. In the } \\
\text { other case, for the first keystroke of the } \\
\text { first word in the sentence, the interval is } \\
\text { about four times as long as that between } \\
\text { the later keystrokes. }\end{array}$ & $\begin{array}{l}\text { This effect also exists in one- } \\
\text { thumb typing. The size of the } \\
\text { effect in the first case is similar to } \\
\text { traditional keyboard typing. In the } \\
\text { other case, when it is the first } \\
\text { keystroke of the first word in the } \\
\text { sentence, the size of the effect is } \\
\text { much larger. }\end{array}$ \\
\hline 11 & $\begin{array}{l}\text { The context phenomenon: the time for a } \\
\text { keystroke is dependent on the specific } \\
\text { context in which the character appears, } \\
\text { especially for the topography of the } \\
\text { keyboard. This is affected by the distance } \\
\text { between two keys as well as the hands and } \\
\text { fingers used to hit the two keys. }\end{array}$ & $\begin{array}{l}\text { The effects of alternative hands and } \\
\text { fingers are not applicable in one-thumb } \\
\text { typing, but the effect of distance also } \\
\text { exists, as can be seen in Figure } 11 \text {. } \\
\text { When interkey distance is longer, the } \\
\text { time is longer. }\end{array}$ & $\begin{array}{l}\text { The effect of distance between } \\
\text { two keys also exists in one-thumb } \\
\text { typing. }\end{array}$ \\
\hline
\end{tabular}




\section{GENERAL DISSUCSSION}

In the current study, we built a model for mobile phone touchscreen typing in QNACTR and tested the model by comparing model results with human results. The model could simulate and predict interkey time performance in both number and sentence typing tasks. We demonstrated the predictive power of the model without adjusting any parameters, as shown in Experiment 2 of this study (model validation).

Comparing the current modeling approach using QN-ACTR with previous MHPbased approaches such as TYPIST (John, 1996) and QN-MHP (Wu \& Liu, 2008), all have previously modeled transcription typing performance using desktop keyboards with both hands. In the current study, we adapted previous QN-ACTR models to transcription typing on touchscreen keyboards using only one hand and one thumb, which is a new development that has not been seen with MHP-based approaches. While we expect that it is also possible to build models for touchscreen typing using MHP-based approaches, a fundamental difference is that MHP-based approaches lack the capability in simulating complex cognitive activities such as reading comprehension. As a result, reading comprehension related transcription typing phenomena are beyond the scopes of TYPIST (John, 1996) and QN-MHP (Wu \& Liu, 2008). In contrast, it has been demonstrated that QN-ACTR is able to capture those phenomena (Cao \& Liu, 2013).

Comparing transcription typing using a touchscreen virtual keyboard versus traditional keyboards, a very unique result on touchscreen is about the word initiation effect and the first keystroke in the sentence. Word initiation effect means that the first keystroke in a word is slower than the subsequent keystrokes. In traditional keyboard typing, the interval before the first key-stroke in a word is approximately $20 \%$ longer 
than that between the later keystrokes (Salthouse, 1986). In the current study, the results can be analyzed in two cases. In the first case, for the first keystroke in a word that is not the first word of the sentence, the interval before it $(461 \mathrm{~ms})$ is $29 \%$ longer than that between the later keystrokes $(356 \mathrm{~ms})$. This result is relatively similar to Salthouse's results. Salthouse suggested that the reason for this effect could be the parsing operation. "The parsing influence could occur because the chunks produced by the input operation are probably grouped on the basis of words, and therefore the speed of isolating characters may be faster within, as opposed to between, these naturally occurring units" (Salthouse, 1986, p. 308). We believe that the same reason also applies to the current study. However in the other case, for the first keystroke of the first word in the sentence, the interval before it (1427 ms) is about four times as long as the later keystrokes (356 ms). This result is obviously different from Salthouse's results. We believe that the cause of this difference is the unique requirement on visual attention when typing on a touchscreen virtual keyboard. In traditional keyboard typing, skilled typists can type while reading the materials at the same time, and there is no need to look at the keyboard. In contrast, when typing on a touchscreen virtual keyboard, users need to look at the keyboard, using visual attention to locate proper keys, as we proposed in Assumption 2 (looking at keys). Users' strategy is expected to be: reading a group of words, then looking at the keyboard, typing the words, and then continuing to read the next group of words. Since the current study showed one sentence in each trial, participants' first keystroke was delayed while they were reading the words. The modeling results captured this first keystroke delay and thus provided support for Assumption 2 and this visual attention explanation to this unique word initiation effect. 
The current model still has its limitations. In the human results of the number typing task, the interkey time at digit position 9 was significantly longer than the values from other following digits, but the model could not capture this effect. Our speculation is that some participants might look at the number for an extra time before typing the $9^{\text {th }}$ digit to confirm the number, whereas the model assumed no such visual scan between the $8^{\text {th }}$ and $9^{\text {th }}$ digits. Since we did not measure participants' eye movement or strategy in the current study, we did not have enough data to examine this speculation. In the model, for each additional visual scan, the interkey time will increase by $235 \mathrm{~ms}$, as the visual scan is completed with three production rules and one event of visual attention shift, following typical ACT-R modeling convention. The first production rule finds the visual location of the unattended visual item $(50 \mathrm{~ms})$; the second production rule visually attends the item (50 ms), which will lead to visual attention shifting $(85 \mathrm{~ms})$; the third production rule encodes the information in the item $(50 \mathrm{~ms})$. Future studies can measure and ask for participants' strategies in order to further examine this issue.

Another limitation is that the model's predictions of interkey time in sentence typing (Experiment 2) were longer than the human results. As shown in Figure 9, the model interkey results at letter positions other than the $1^{\text {st }}$ letter were longer than the human average and outside of the $95 \%$ confidence intervals. A potential explanation is the speed-accuracy tradeoff. Since the participants were not required to correct typing errors in the current study, they may trade accuracy for faster typing speed, which could make their interkey time shorter. The current model has not considered typing errors. Future work could build upon the current model and add the consideration of typing errors and speed-accuracy tradeoff in the model. 
In addition, a potential limitation of the current study is the relatively small number of participants in Experiment $2(N=10)$. We believe that it is not a major issue because the number typing results of Experiment 2 replicated that of Experiment 1, which had a larger sample size, and the sentence typing results from each participant were averaged from 80 trials, with a total of over 2000 characters typed per person on average. Nevertheless, future studies can repeat the experiment with a larger number of participants to further verify the results.

Regarding future work, studies are also needed to examine and model performance from typing tasks in which users are required to compose the messages rather than read them from transcription. In that case, some of the transcription typing phenomena due to parsing or chunking operations are expected to become different. In addition, the current study focused on portrait phone orientation and one hand typing, the cases of two-thumb typing and landscape orientation can also be a direction of future follow-up work.

\section{CONCLUSION}

In the current study, we developed a model using the QN-ACTR cognitive architecture for the simulation of transcription typing tasks on a touchscreen keyboard. The tasks are different from typing using desktop keyboards because only one hand and one thumb finger were used on the touchscreen. Human data were collected from both number typing and sentence typing tasks, showing that this type of typing is much slower than traditional desktop keyboard typing, especially for the first keystroke of a sentence. The predictive power of the model was demonstrated in simulating the sentence typing interkey time performance without adjusting any parameters. The modeling results produced good fit in general to the human interkey time results analyzed by both key 
position in a number or word and interkey distance between two consecutive keystrokes. The findings demonstrated the method's capability in capturing both perceptual factors (chunking of the reading materials) and motor factors (Fitt's law) in transcription typing time performance. As part of the integrated cognitive architecture approach, the model developed in the current study can be further integrated with models for other tasks in order to simulate complex multitasking performance such as typing while driving, which is one of our future research goals. 


\section{REFERENCES}

Anderson, J. R., Bothell, D., Byrne, M. D., Douglass, S., Lebiere, C., \& Qin, Y. (2004). An integrated theory of the mind. Psychological Review, 111(4), 1036-1060.

Byrne, M. D., \& Anderson, J. R. (1998). Perception and action. In J. R. Anderson \& C. Lebiere (Eds.), The Atomic Components of Thought (pp. 167-200). Mahwah, NJ: Lawrence Erlbaum.

Cao, S., \& Liu, Y. (2012). An Integrated Cognitive Architecture for Cognitive Engineering Applications. Proceedings of the Human Factors and Ergonomics Society Annual Meeting, 56(1), 323-327.

Cao, S., \& Liu, Y. (2013). Queueing network-adaptive control of thought rational (QNACTR): An integrated cognitive architecture for modelling complex cognitive and multi-task performance. International Journal of Human Factors Modelling and Simulation, 4(1), 63-86.

Card, S. K., Moran, T. P., \& Newell, A. (1980). The Keystroke-level Model for User Performance Time with Interactive Systems. Commun. ACM, 23(7), 396-410.

Card, S. K., Moran, T. P., \& Newell, A. (1983). The Psychology of Human-Computer Interaction. London: Lawrence Erlbaum Associates.

Fitts, P. M. (1954). The information capacity of the human motor system in controlling the amplitude of movement. Journal of Experimental Psychology, 47(6), 381391.

Gentner, D. R. (1983). The acquisition of typewriting skill. Acta Psychologica, 54(1-3), 233-248. https://doi.org/10.1016/0001-6918(83)90037-9 
Greene, K. K., \& Gallagher, M. A. (2014). Support for ACT-R Modeling of Elliptical Endpoint Error Distributions in Mobile Touchscreen 2-D Fitts' Law Tasks. Human-Computer Interaction, 7, 91-139.

Greene, K. K., \& Tamborello, F. (2013). Initial ACT-R extensions for user modeling in the mobile touchscreen domain. In Proceedings of the 12th International Conference on Cognitive Modeling.

He, J., Chaparro, A., Nguyen, B., Burge, R. J., Crandall, J., Chaparro, B., .. Cao, S. (2014). Texting while driving: Is speech-based text entry less risky than handheld text entry? Accident Analysis \& Prevention, 72(0), 287-295. https://doi.org/10.1016/j.aap.2014.07.014

Hoggan, E., Brewster, S. A., \& Johnston, J. (2008). Investigating the Effectiveness of Tactile Feedback for Mobile Touchscreens. In Proceedings of the SIGCHI Conference on Human Factors in Computing Systems (pp. 1573-1582). New York, NY, USA: ACM. Retrieved from http://doi.acm.org/10.1145/1357054.1357300

Holleis, P., Otto, F., Hussmann, H., \& Schmidt, A. (2007). Keystroke-level Model for Advanced Mobile Phone Interaction. In Proceedings of the SIGCHI Conference on Human Factors in Computing Systems (pp. 1505-1514). New York, NY, USA: ACM. Retrieved from http://doi.acm.org/10.1145/1240624.1240851

Horrey, W. J., \& Wickens, C. D. (2004). Driving and side task performance: The effects of display clutter, separation, and modality. Human Factors: The Journal of the Human Factors and Ergonomics Society, 46(4), 611-624. https://doi.org/10.1518/hfes.46.4.611.56805 
James, C. L., \& Reischel, K. M. (2001). Text Input for Mobile Devices: Comparing Model Prediction to Actual Performance. In Proceedings of the SIGCHI Conference on Human Factors in Computing Systems (pp. 365-371). New York, NY, USA: ACM. Retrieved from http://doi.acm.org/10.1145/365024.365300

John, B. E. (1996). TYPIST: A theory of performance in skilled typing. HumanComputer Interaction, 11(4), 321-355.

John, B. E., \& Kieras, D. E. (1996). The GOMS Family of User Interface Analysis Techniques: Comparison and Contrast. ACM Transactions on Computer-Human Interaction, 3(4), 320-351.

Keith, N., \& Ericsson, K. A. (2007). A deliberate practice account of typing proficiency in everyday typists. Journal of Experimental Psychology. Applied, 13(3), 135145.

Kieras, D. E., \& Meyer, D. E. (1997). An Overview of the EPIC Architecture for Cognition and Performance with Application to Human-computer Interaction. Hum.-Comput. Interact., 12(4), 391-438.

Liu, Y. (1996). Queueing network modeling of elementary mental processes. Psychological Review, 103(1), 116-136.

Liu, Y. (1997). Queueing network modeling of human performance of concurrent spatial and verbal tasks. IEEE Transactions on Systems, Man, Cybernetics, 27(2), 195207.

Liu, Y. (2007). Queuing network modeling of mental architecture, response time, and response accuracy: Reflected multidimensional diffusions. In Proceedings of the 2007 International Conference on Cognitive Modeling. 
Liu, Y., Feyen, R., \& Tsimhoni, O. (2006). Queueing Network-Model Human Processor (QN-MHP): A computational architecture for multitask performance in humanmachine systems. ACM Transactions on Computer-Human Interaction, 13(1), 3770.

Liu, Y., Wu, C., \& Berman, M. G. (2012). Computational neuroergonomics. Neuroergonomics: The Human Brain in Action and at Work, 59(1), 109-116.

Logan, G. D., \& Crump, M. J. C. (2009). The left hand doesn't know what the right hand is doing: the disruptive effects of attention to the hands in skilled typewriting. Psychological Science, 20(10), 1296-1300.

MacKenzie, I. S., Nonnecke, R. B., McQueen, J. C., Riddersma, S., \& Meltz, M. (1994). A Comparison of three Methods of Character Entry on Pen-Based Computers. Proceedings of the Human Factors and Ergonomics Society Annual Meeting, $38(4), 330-334$.

MacKenzie, I. S., \& Soukoreff, R. W. (2002a). A model of two-thumb text entry. In Proceedings of Graphics Interface 2002 (pp. 117-124).

MacKenzie, I. S., \& Soukoreff, R. W. (2002b). Text Entry for Mobile Computing: Models and Methods, Theory and Practice. Human-Computer Interaction, 17(2 \& 3), 147-198.

MacKenzie, I. S., \& Zhang, S. X. (1999). The design and evaluation of a highperformance soft keyboard. In Proceedings of the SIGCHI conference on Human Factors in Computing Systems (pp. 25-31). Pittsburgh, Pennsylvania, USA: ACM. 
Reed, M. P., \& Green, P. A. (1999). Comparison of driving performance on-road and in a low-cost simulator using a concurrent telephone dialling task. Ergonomics, 42(8), 1015-1037.

Salthouse, T. A. (1984). Effects of age and skill in typing. Journal of Experimental Psychology: General, 113(3), 345-371.

Salthouse, T. A. (1985). Anticipatory processing in transcription typing. Journal of Applied Psychology, 70(2), 264-271.

Salthouse, T. A. (1986). Perceptual, cognitive, and motoric aspects of transcription typing. Psychological Bulletin, 99(3), 303-319.

Salthouse, T. A., \& Scott, J. (1987). Multiple spans in transcription typing. Journal of Applied Psychology, 72(2), 187-196.

Salvucci, D. D. (2005). A multitasking general executive for compound continuous tasks. Cognitive Science, 29(3), 457-492. https://doi.org/10.1207/s15516709cog0000_19

Silfverberg, M., MacKenzie, I. S., \& Korhonen, P. (2000). Predicting Text Entry Speed on Mobile Phones. In Proceedings of the SIGCHI Conference on Human Factors in Computing Systems (pp. 9-16). New York, NY, USA: ACM.

St. Amant, R., Goodwin, P. R., Dominguez, I., \& Roberts, D. L. (2015). Toward expert typing in ACT-R. In Proceedings of the 2015 International Conference on Cognitive Modeling (pp. 232-237).

Turner, C. J., Chaparro, B. S., \& He, J. (2017). Text Input on a Smartwatch QWERTY Keyboard: Tap vs. Trace. International Journal of Human-Computer Interaction, 33(2), 143-150. https://doi.org/10.1080/10447318.2016.1223265 
Wu, C., \& Liu, Y. (2007). Queuing Network modeling of driver workload and performance. IEEE Transactions on Intelligent Transportation Systems, 8(3), $528-537$.

Wu, C., \& Liu, Y. (2008). Queuing Network Modeling of Transcription Typing. ACM Transactions on Computer-Human Interaction, 15(1), 6:1-6:45. 